\title{
Isolation and Multiple Drug Resistance Patterns of Salmonella Isolates from Selected Dairy Farms in Hawassa Town, Ethiopia
}

\begin{abstract}
Keywords: Dairy farms; Isolation; Hawassa; Multiple drug; Antimicrobial resistance; Salmonella

Abstract

A cross-sectional study was conducted from November 2017 to May 2018 on selected dairy farms in Hawassa town to isolate and assess the in-vitro antibiotic biogram of Salmonella from lactating dairy cows, personnel's and equipments at farms. A total of 216 samples were collected from selected dairy farms. All samples were processed bacteriologically following standard procedures outlined by ISO 6579 : 2002. The overall prevalence of Salmonella was $12.9 \%(28 / 216)$ of the total samples. Out of total, $64.3 \%(18 / 28), 10.7 \%(3 / 28)$ and $25 \%(7 / 28)$ were from lactating cows, personnels', and equipments, respectively. Based on antimicrobial susceptibility testing, all isolates were resistant at least to one or more antimicrobials tested. Accordingly, $96.4 \%$ (27/28), $82.1 \%(23 / 28)$ and $75.0 \%(21 / 28)$ isolates showed resistance for oxytetracycline, kanamycin, and nalidixic acid, respectively. Out of all the resistant isolates, $96.4 \%(27 / 28)$ showed multiple antibiotic resistance (resistance to two or more antibiotics) patterns. Multiple antimicrobials resistance was observed in $66.7 \%$ (18/27), 7.4\% (2/27) and 25.9\% (7/27) from lactating cows, personnels', and equipments, respectively. Thus, awareness creation to the public regarding the public health importance of multiple drug-resistant Salmonella species and the consumption of unpasteurized milk and milk products is important.
\end{abstract}

\section{Introduction}

Milk has been described as a nearly perfect food since it contains the vital nutrients essential to the body, but it is also considered as a good medium for many microorganisms [1]. Raw untreated milk is still used by a large number of farm families and workers. In the raw milk value chain, milk producers, vendors and shop outlets can influence the prevalence of harmful pathogens in milk through poor animal husbandry, adulteration, washing equipment, udder and hands with unsafe water, storing and transportation in unhygienic condition and abuse of storage temperature [2]. Especially, the safety of dairy products with respect to foodborne diseases is a major global issue especially in the developing countries where production of milk and milk products takes place under poor hygienic, sanitary and Agricultural practices [3]. Milk contamination by zoonotic pathogenesis often natural but can also occur through handling milk in unhygienic conditions $[1,4]$.

Food-borne bacterial diseases are a serious challenge to public health in developed and developing countries. There are more than 250 different food-borne diseases and most of these diseases are infections, caused by a variety of bacteria, viruses, parasites, and poisonings caused by harmful toxins or chemicals like poisonous mushrooms [5,6]. There different bacteria that cause foodborne diseases such as Salmonella, Campylobacter, Listeria, pathogenic Escherichia coli, Yersinia, Shigella, and Enterobacter. Salmonella is

\section{Journal of}

Veterinary Science \& Medicine

\author{
Fesseha $\mathrm{H}^{*}$, Aliye S, Kifle T and Mathewos M \\ School of Veterinary Medicine, Wolaita Sodo University, Ethiopia \\ *Address for correspondence: \\ Haben Fesseha, School of Veterinary Medicine, Wolaita Sodo Univer- \\ sity, Ethiopia, PO Box 138, Wolaita Sodo, Southern, Ethiopia; E-mail: \\ tseyon.h@gmail.com \\ Submission: 20-January-2020 \\ Accepted: 21-February-2020 \\ Published: 22- February-2020 \\ Copyright: ( $\odot 2020$ Fesseha H Heredia Peralta DT, et al. This is an \\ open access article distributed under the Creative Commons Attribution \\ License, which permits unrestricted use, distribution, and reproduction in \\ any medium, provided the original work is properly cited.
}

one of the most important bacterial species that infect a wide variety of hosts including humans and numerous farm animals; such as pigs, cattle, horses, and chickens [7].

Salmonella is comprised of different species and more than 2,600 different serovars of Salmonella have been characterized based on the surface ' $O$ ' antigen, which is a part of the variable long chain of lipopolysaccharide on the bacterial outer membrane [8]. Out of these 2,600 serovars, nearly 1500 belong to the Salmonella subspecies enterica. Serovars of the enterica subspecies can be divided into three groups depending upon their ability to infect a wide variety of hosts. The first group includes serovars that have a broad host range also called unrestricted serovars as these infect nearly all animals. This group includes serovars like Salmonella typhimurium and Salmonella enteritidis. Nevertheless, these serovars are of high importance with respect to their epidemiology as these have developed mechanisms to invade different hosts without any greater resistance. Thus, these serovars pose a greater zoonotic potential than their other counterparts [9].

The second group includes serovars that cause highly severe systemic infection in their preferred host and are usually excreted without any clinical symptoms when they accidentally infect hosts others than their most adapted or preferred. Serovars such as Dublin, Choleraesuis fall into this category, as these prove to only cause systemic infection in cattle and pigs respectively [10]; however, these upon infection into other hosts like rodents and humans are usually excreted making these hosts as 'carriers'. Serovars of this group are referred to as the 'Host-adapted Serovars'. The third group comprises of serovars which are restricted very strictly with one very specific host only; these serovars are called 'host restricted serovars'. They exclusively cause systemic infection, which often proves to be fatal within their host. Serovars such as Typhi, Gallinarum, Abortus equi, ectecra belong to this group [11]

Salmonella is transmitted to animals and humans through consumption of contaminated food products (milk, eggs, and meats), direct contact with infected animals, through contaminated equipments such as stainless steel, hanging material, bucket, where milk is collected and stored, are a key mechanism for pathogens to contaminate food products [12]. In livestock, clinical signs typically appear 6-24 hr after exposure and include profuse diarrhea, fever, 
dehydration, in appetence, foul-smelling feces, and mucus or blood in feces [13]. Disease manifestations in people include diarrhea, fever, abdominal cramps and septicemia in severe cases, appearing 12-72 hr after ingestion. Salmonella can also be carried subclinically by both humans and animals $[14,15]$.

The prevalence of salmonella infection varies across regions, however, the diseases caused by $\mathrm{S}$. enteric serovars are especially prevalent in developing areas, such as Southeast Asia, Africa and South America that leads to an estimated 20 million cases of humans and 200,000 deaths each year. Challenges such as antibiotic-resistant Salmonella strains also pose a significant threat to deliver reliable therapies [16]. In Ethiopia, as in other developing countries, it is difficult to evaluate the burden of Salmonellosis because of the limited scope of studies and the lack of coordinated epidemiological surveillance systems. In addition, under-reporting of cases and the presence of other diseases considered to be of high priority may have overshadowed the problem of Salmonellosis. Continuous surveillance of the prevalent Salmonella serovars and assessing their antimicrobial resistance pattern is essential to control the spread of the pathogen [17].

Antibiotic resistance in Salmonella is a rising problem over the past decades. Improper use of antibiotics in both human and veterinary medication has caused bacteria to develop resistance against therapeutic antibiotics $[18,19]$. Using antimicrobial agents for cattle has been implicated as a source of human infection with Antimicrobial-Resistant (AMR) Salmonella through direct contact with livestock and consumption of raw milk, meat and contaminated material [20]. Antimicrobial-resistant Salmonella are increasing due to the use of antimicrobial agents in food animals at subtherapeutic level or prophylactic doses that may promote growth and markedly increase the human health risks associated with consumption of contaminated milk and meat products through mutation, acquisition of resistance encoding genes and irrational use of antimicrobials in food animals [21-23]

Accordingly, there are limited studies regarding the assessment of the pathogens isolated from apparently healthy animals at farm level, personnels' and different types of equipment. Thus, the screening of milk and other dairy products against pathogenic organisms will play a vital role in curtailing human infection. Studying the prevalence and antimicrobial resistance of Salmonella from cattle and in contact with humans in dairy farms is the most important to design methods of minimizing the possible transmission of Salmonella between humans and cattle. Moreover, it important in combating the emergence of antibiotic-resistant strains of Salmonella [11]. Hence, this study was conducted to isolate, identify and assess the multiple drug resistance pattern of Salmonella isolates from selected dairy farms in Hawassa town.

\section{Materials and Methods}

\section{Study area}

The current study was conducted from November 2017 to May 2018 in selected dairy cattle farms of Hawassa towns. It is located 275 $\mathrm{km}$ south of Addis Ababa. Hawassa is situated at an altitude of $1750 \mathrm{~m}$ above sea level and according to an estimate, it lies between $6^{\circ} 83^{\prime}$ to $7^{\circ} 17^{\prime} \mathrm{N}$ and $38^{\circ} 24^{\prime}$ to $38^{\circ} 72^{\prime} \mathrm{E}$. Hawassa receives an average annual rainfall of $955 \mathrm{~mm}$ with mean annual temperature of $20^{\circ} \mathrm{C}$ and the city has a total area of about $50 \mathrm{~km}^{2}$ divided into eight sub-cities and 32 kebeles (kebeles are the smallest administrative unit below the subcity/woreda level) [24].

\section{Study population}

The study animals were apparently healthy dairy cows that were located in Hawassa town. The study includes dairy cattle kept under different (extensive, intensive and semi-intensive) management systems as well as farm personnels and equipments. There are different types of farms including small, medium and large scale having dairy cattle ranging from five to twenty two. Besides, the farms were selected purposively based on the availability of lactating cows and the willingness of the owners.

\section{Study design and Sampling technique}

A cross-sectional study was carried out from November 2017 to May 2018 to isolate, identify and assess the multi-drug resistance pattern of the salmonella isolates from selected dairy farms. The farms are selected purposively based on the availability and accessibility of study animals. Accordingly, a total of 216 samples were collected from selected dairy cattle farms in the study area.

\section{Sample collection, handling and transportation}

Samples were collected aseptically from apparently dairy cows (milk and feces), hands of personnel working in the farms and from equipment (container and buckets). Then the all samples were collected after getting proper consent from the personnel and Hawassa university to perform the research activity. Fecal samples were collected directly from the rectum and put into $50 \mathrm{ml}$ containing a universal screwed capped bottle and $10 \mathrm{ml}$ of milk was collected aseptically from all teats in a sterile test tube after aseptically preparing the teats thorough scrubbing with a cotton moistened with $70 \%$ denatured alcohol and the first 3-4 streams of milk were discarded. All types of swab samples (milkers' hand, container and buckets) were collected before the commencement of the milking process using a sterile wooden cotton swab and were put into a sterile test tube containing $10 \mathrm{ml}$ buffered peptone water used as transport media. All sample types were properly labeled with permanent marker. Then, the samples were immediately transported using an icebox to the Microbiology Laboratory of Hawassa University for further bacteriological examination.

\section{Isolation and identification of salmonella}

The isolation and identification of Salmonella was performed at the Microbiology laboratory of Hawassa University by using techniques recommended by International Organizations for Standardization (ISO-6579, 2002) [25]. The detection of salmonella was performed based on the following four successive stages: Firstly, All samples were pre-enriched in non-selective liquid media and processed separately. Then, $1 \mathrm{gm}$ of fecal sample and $1 \mathrm{ml}$ of milk was pre-enriched with $9 \mathrm{ml}$ of Buffered Peptone Water (BPW) and incubated for $24 \mathrm{hrs}$ at $37^{\circ} \mathrm{C}$. Secondly, all samples were transferred to selective media such as Tetrathionate Broth and Rappaport Vassiliadis Salmonella Enrichment Broth. A $1 \mathrm{ml}$ of pre-enriched sample was transferred aseptically into a tube containing $10 \mathrm{ml}$ of Tetrathionate Broth and incubated at $37 \pm 1{ }^{\circ} \mathrm{C}$ for $24 \pm 3$ hours. Another $0.1 \mathrm{ml}$ of the culture 
Figure 1: Proportion of Salmonella isolates from different samples types.

Table 1: Antibiotic Susceptibility Profiles of Salmonella isolates in dairy farms.

\begin{tabular}{|c|c|c|c|}
\hline \multirow{2}{*}{ Antibiotics disc } & \multicolumn{3}{|c|}{ Antibiotic Susceptibility Patterns } \\
\hline & Sensitive (\%) & Intermediate (\%) & Resistance (\%) \\
\hline Amoxacillin & $10(35.7)$ & $11(39.3)$ & $7(25.0)$ \\
\hline Cefoxitin & $25(89.3)$ & $0(0.00)$ & $3(10.7)$ \\
\hline Chloramphenicol & $14(50.0)$ & $9(32.1)$ & $5(17.9)$ \\
\hline Ciprofloxacin & $27(96.4)$ & $0(0.00)$ & $1(3.6)$ \\
\hline Gentamycin & $28(100.0)$ & $0(0.00)$ & $0(0.00)$ \\
\hline Kanamycin & $2(7.1)$ & $3(10.7)$ & $23(82.1)$ \\
\hline Nalidixic acid & $0(0.00)$ & $7(25.0)$ & $21(75.0)$ \\
\hline Oxytetracycline & $0(0.00)$ & $1(3.6)$ & $27(96.4)$ \\
\hline Streptomycin & $16(57.1)$ & $9(32.1)$ & $3(10.7)$ \\
\hline Trimethoprim-sulphamethaxazole & $22(78.6)$ & $3(10.7)$ & $3(10.7)$ \\
\hline
\end{tabular}

obtained in pre-enrichment broth was transferred aseptically into a tube containing $10 \mathrm{ml}$ Rappaport Vassiliadis Salmonella Enrichment Broth (Harmonized) and incubated at $41.5 \pm 1^{\circ} \mathrm{C}$ for $24 \pm 3 \mathrm{hrs}$.

Thirdly, Plating out and identification of the samples were conducted using Xylose lysine Desoxycholate (XLD) agar and Salmonella-Shigella (SS) agar plates. A loopful of inoculum from cultures of the selective enrichment media were streaked on to XLD and SS agar plates and incubated at $37^{\circ} \mathrm{C}$ for $24 \mathrm{hrs}$. Then, all colonies that grow on the XLD medium, produces hydrogen sulfide $\left(\mathrm{H}_{2} \mathrm{~S}\right)$ and colorless colonies with black center on SS medium were streaked onto Nutrient Agar and incubated at $37^{\circ} \mathrm{C}$ for $24 \mathrm{hrs}$ for further confirmation through serious of biochemical tests. Finally, All suspected colonies were subjected to a series of different biochemical tests using the procedure of (ISO 6579, 2002; to confirm salmonella [25]. Triple Sugar Iron Agar (TSIA), Urease, Citrate, Indole, Methyl red and Voges Proskouer (VP) tests were performed on all suspected isolates to confirm the salmonella. All presumptive salmonella Isolate were cultured on Nutrient Agar for further antimicrobial susceptibility testing.

\section{Antimicrobial susceptibility test}

The antibiotic susceptibility tests of the Salmonella isolates were performed according to the Clinical and Laboratory Standards Institute (CLSI) method using Kirby-Bauer disk diffusion test on Muller-Hinton Agar (HIMEDIA, India) [26]. Pure colonies on nutrient agar were taken with a wire loop and transferred to a tube containing $5 \mathrm{ml}$ of Saline water and emulsified. The broth culture was incubated at $37^{\circ} \mathrm{C}$ for $4 \mathrm{hrs}$ until it achieved the $0.5 \mathrm{McF}$ arland turbidity standards. Sterile cotton swab was dipped into the suspension and the bacteria were swabbed uniformly over the surface of MullerHinton agar plate within a sterile safety cabinet. The plates were held at room temperature for 15 minutes to allow drying. Antibiotic discs with a known concentration of antimicrobials were placed and the plates were incubated for $24 \mathrm{hrs}$ at $37^{\circ} \mathrm{C}$.

Amoxicillin (AML) $(25 \mu \mathrm{g})$, Cefoxitin (FOX) $(30 \mu \mathrm{g})$, Chloramphenicol (C) $(30 \mu \mathrm{g})$, Gentamycin (CN) $\quad(10 \mu \mathrm{g})$, Streptomycin (S) $(10 \mu \mathrm{g})$, Kanamycin (K) $(30 \mu \mathrm{g})$, Nalidixic acid (NA) $(30 \mu \mathrm{g})$, Ciprofloxacin (CIP) $(5 \mu \mathrm{g})$, Oxytetracycline (OT) $(30 \mu \mathrm{g})$ and Trimethoprim-sulphamethoxazole (SXT) $(25 \mu \mathrm{g})$, were selected based on availability and their current use in human and veterinary medicine. All the antibiotics were from Oxiod Hampshire, England, and the expiry date was properly checked before application. Zone of inhibition of individual antibiotic agent was interpreted in to susceptible, intermediate, and resistance categories by referring recommended clinical and laboratory standards institute [26].

\section{Data analysis}

Data collected from field and laboratory investigations were recorded, and coded using Microsoft Excel 2013 program and analyzed using STATA version 13.0. Descriptive statistics were used to figure out the proportions of Salmonella isolate. Moreover, the antibiotic efficacy of each drug was determined by comparing the 
Citation: Fesseha H, Aliye S, Kifle T, Mathewos M. Isolation and Multiple Drug Resistance Patterns of Salmonella Isolates from Selected Dairy Farms in Hawassa Town, Ethiopia. J Veter Sci Med. 2020;8(1): 7.

ISSN: $2325-4645$

Table 2: Multiple antibiotic resistance MAR profile of Salmonella isolates.

\begin{tabular}{|c|c|c|c|}
\hline MAR pattern & Number of isolates & Multiple drug resistance patterns & Number of isolates (\%) \\
\hline \multirow{2}{*}{ Two } & 3 & OT, NA, & \multirow{2}{*}{$5(18.5)$} \\
\hline & 2 & OT, K & \\
\hline \multirow{2}{*}{ Three } & 7 & OT, K, NA & \multirow{2}{*}{$8(29.6)$} \\
\hline & 1 & $\mathrm{OT}, \mathrm{K}$ & \\
\hline \multirow{6}{*}{ Four } & 2 & $\mathrm{NA}, \mathrm{OT}, \mathrm{K}$ & \multirow{6}{*}{$7(25.9)$} \\
\hline & 1 & OT, CIP, C & \\
\hline & 1 & OT, AML NA & \\
\hline & 1 & NA, OT, SXT, K & \\
\hline & 1 & OT, AML, SXT, K & \\
\hline & 1 & NA, S, OT, K & \\
\hline \multirow{3}{*}{ Five } & 1 & NA, C, OT, K & \multirow{3}{*}{$4(14.8)$} \\
\hline & 2 & OT, AML, K, NA & \\
\hline & 1 & FOX, C, OT, K, NA & \\
\hline Six & 1 & FOX, S, AML, K, NA & $1(3.7)$ \\
\hline Eight & 1 & $\mathrm{~S}, \mathrm{C}, \mathrm{OT}, \mathrm{AML}, \mathrm{K}, \mathrm{NA}, \mathrm{FOX}$ & $1(3.7)$ \\
\hline
\end{tabular}

zone of inhibition with the standard one.

\section{Results}

\section{Frequency of Salmonella isolates}

In this study, out of 216, the overall prevalence of Salmonella was $12.9 \%(28 / 216)$. From the overall proportion, $64.3 \%$ (18/28), $10.7 \%$ $(3 / 28)$ and $25 \%(7 / 28)$ were isolated from the milk and feces of dairy cows, personnel and equipments, respectively. 19\% of Salmonella were isolated from plastic container milk. A higher proportion of Salmonella was isolated from milk samples (12.1\%) than fecal samples (7.7 \%) (Figure 1)

\section{Antimicrobial susceptibility of Salmonella isolates}

In the present study, out of 28 isolates, 27 isolates showed multiple drug resistance. Accordingly, all isolates were susceptible to ciprofloxacin, cefoxitin and trimethoprim-sulphamethoxazole with proportion of $96.4 \%, 89.3 \%$, and $78.6 \%$, respectively. However, all isolates were $96.4 \%, 82.1 \%$ and $75.0 \%$ resistant to oxytetracycline, kanamycin and nalidixic acid, respectively. On the other hand, all isolates were $100 \%$ sensitive to gentamycin (Table 1).

\section{Multiple drug resistance patterns of Salmonella isolates}

Multiple drug resistance (isolates that were resistant for two or more antibiotics) were detected in $96.4 \%(27 / 28)$ of the Salmonella isolates. Out of these, $66.7 \%$ (18/27), 7.4\% (2/27) and 25.9\% (7/27) isolates were from lactating cows, personnels', and equipments, respectively. The higher multi-drug resistance pattern was observed in $\mathrm{K}, \mathrm{NA}, \mathrm{OT}$, with the proportion of $25.9 \%$ followed by K, NA, OT, AML with the proportion of $7.4 \%$. Besides, $11.1 \%$ of the resistant isolates were resistant to six and more antibiotics (Table 2).

\section{Discussion}

In this study, out of 216 samples collected from selected dairy farms in Hawassa town, the overall proportion of Salmonella isolated from dairy cows, personnels' and equipment were $12.9 \%$. This was higher than the reports of where $7.2 \%$ were found in slaughtered small ruminants and environment in Modjo export abattoir [27], $7.1 \%$ from apparently healthy slaughtered cattle in Debre Zeit and the study on cheese and milk in Debre Zeit (2.1\%) as well as dairy product in Addis Ababa (1.6\%) [21,28-30]. However, the current finding was comparable with $10.5 \%$ from apparently healthy dairy cows in Modjo [31], 10.76\% from lactating cows and in contact humans in dairy farms of Addis Ababa and (11.5\%) among chicken table eggs at Kombolcha [18], Ethiopia [32]. The present result was lower than the findings of who reported $20 \%$ in raw milk from the Korsa district and Ejeta et al., 2004 who reported 14.7\% from minced beef, mutton and pork samples among supermarkets in Addis Ababa [33].

In this study, the prevalence of Salmonella from milk and feces of apparently healthy lactating dairy cows was $64.3 \%$. This was higher than who reported $7.1 \%$ from apparently healthy slaughtered cattle [28]. This variation could be due to the test procedures and techniques used since pre-enrichment steps using buffered peptone water was employed in this study and source of sample. Similarly, the report of [34]; from England ( $0.2 \%$ and $4 \%$ ), from Northern Thailand (3\%) and from Cameroon (27\%) are much lower than the current study $[35,36]$. The current result was higher than the prevalence recorded in Iran 4\% and in USA 7.3\% and in Nigeria (15\%) and 10.9\% reported in Namibia on bovine and ovine bone-and-meat meal and blood meal samples $[19,37,38]$. This may be attributed to the variation in agroecological location of the cattle, housing conditions, feeding habits, and types of feed provided for the cattle.

According to the current investigation, Salmonella was isolated from the fecal samples of apparently healthy lactating dairy cows with a rate of $7.7 \%$. This finding was higher than the report of from Egypt where prevalence in on fecal shedding of Salmonella among dairy cattle was 1.56 [39]. However, this result was lower than from the United States (9.7\%) [40], from central Texas [41], USA where Salmonella shedding rate from fecal samples of dairy calf was $70 \%$. This huge difference might be in the report from Texas, all isolates were one serotype (S. kinshasa) and this serotype might have specific host requirement.

In the present study, Salmonella was isolated from milkers' hand swab with a rate of $14.3 \%$. This was higher than the report of (8.9\%) from small ruminants slaughtered in Modjo export abattoir [27]. However, it was lower than the work of Beyene et al., 2016 (28.6\%) from pooled milkers' hand swab of personnels' working in Asella Municipal abattoir. 
The variation in the prevalence of Salmonella isolation between the present-day study and the previous studies at different areas of the country could be associated with different risk factors that contribute to the occurrence of Salmonella. These are host-related risk factors that include age, breed, the physiological state of the animals, feeding strategies, vaccination status [29]. Environment-related risk factors are often related to hygienic and management practice, stocking density, type and amounts of feed, accessible water supplies, infection load in the environment, usage of contaminated utensil, housing type, ventilation, flooded grassing areas, movement of animals, calving environment, and production facilities in different areas are also plays a role for Salmonella occurrence [12]. Additionally, epidemiological patterns of Salmonella differ greatly between geographical areas depending on climate, population density, land use, farming practice, food harvesting and processing technologies and consumer habits [42].

The current study revealed that $96.4 \%$ of the isolates were resistant for two or more antibiotics which was comparable with the finding of [31]. However, it was higher than the previous studies conducted in Ethiopia and elsewhere in the world [21,28,43-46]. This difference may be due to the increasing rate of inappropriate utilization of antibiotics in the dairy farms which favors selection pressure that increased the advantage of maintaining resistance genes in bacteria $[47,48]$.

The result of the current research indicated Salmonella isolates were resistant to Oxytetracycline, kanamycin, and nalidixic acid with a resistance rate of $96.4 \%, 82.1 \%$, and $75 \%$ respectively. Similarly, reported that the isolates of Salmonella from food items and personnel from Addis Ababa were resistant to the commonly used antibiotics including streptomycin [21], and oxytetracycline. However, resistance rates to oxytetracycline are very high compared to results documented in America reported 95.6\% and 87.8\% sensitivity levels [37], respectively and Iran reported $42.58 \%$ sensitivity for both antibiotics [19]. In this study, $96.4 \%$ of the isolates showed resistance to two or more antibiotics which is lower than a report from Addis Ababa, Ethiopia (83\%) [18].

According to the study, Salmonella isolates were susceptible to gentamycin and ciprofloxacin with the rate of susceptibility $100 \%$ and $96.4 \%$ respectively. This was in agreement with the reports of where Salmonella isolated from apparently healthy slaughtered sheep in Turkey showed $100 \%$ sensitivity to these antibiotics [36], with and with the report of in Iran where ciprofloxacin was $100 \%$ effective $[19,30]$. However, it was higher than who reported $73.3 \%$ and $83.3 \%$ [11], who reported $75 \%$ and $95 \%$ for ciprofloxacin and gentamycin, respectively [33]. This variation might be due to small sample sizes for the data, nature of the drug, presence of different strains of the bacteria, development of resistant gene, their low-frequency usage for prevention and control of disease in food animals in the study area.

The present study revealed that Salmonella isolates were resistant to tetracycline and ampicillin with a rate of $96.4 \%$ and $39 \%$, respectively which disagrees with the report of in Egypt reported that each of the ampicillin and tetracycline was $85.7 \%$ effective against Salmonella species isolated in dairy cattle [39]. In addition, in the present study trimethoprim-sulphamethoxazole was an effective drug (78.6\%) against salmonella isolates that disagrees with the report by who reported $100 \%$ resistance to trimethoprim-sulphamethoxazole [39]. A higher activities of gentamycin (100\%) observed in the current study disagree with a study in Texas, USA, reported $85 \%$ and this difference might be due to availability and overuse of the drug in the farm of the current study [41]. In the current study, ciprofloxacin was $96.4 \%$ effective against all isolates which was in line with a report in Sudan where ciprofloxacin was $100 \%$ effective to all human and cattle Salmonella isolates [49]. The result for streptomycin resistance in this study (10.7\%) was lower than $13.3 \%$ and $25 \%$, which was reported by and $[18,33]$, respectively. Amoxicillin resistance in this study (25\%) was higher than $16.7 \%$ reported by [30]. The resistance of chloramphenicol in this study $17.9 \%$ is consistent with $16.7 \%$ reported by and $[18,30]$, and lower than $25 \%$ reported by [33].

According to the antimicrobial susceptibility testing, all of the isolates showed multiple drug resistance to at least one or more drugs tested were observed which was in line with the report of $[30,33,50]$. Moreover, $96.4 \%$ of the isolates showed multiple drug resistance for two or more types of antimicrobials. This was higher as compared to the report of who reported $70 \%$ and $30 \%$ [33], who report $83.3 \%$ and $16.3 \%$ [50], and who reported $50 \%$ and $50 \%$ for multiple and single antimicrobial resistance, respectively [30].

In general, antimicrobial use is a key driver of resistance development, which is either overuse for minor infectious, misuse due to lack of access to appropriate treatment and underuse due to inadequate dosing, poor adherence or substandard antimicrobial and lack of financial support to complete treatment course. The present study indicated the importance of cattle products (milk), personnel working in the farms and materials/equipment used as a potential source of Salmonella infection.

\section{Conclusion and Recommendations}

In the present study, the isolation of $12.9 \%$ Salmonella at dairy farms level showed that dairy cattle and their environment are important sources of milk contamination with the organism, and consumption of raw milk and other unpasteurized dairy products can lead to infection with zoonotic Salmonellosis. The presence of a high proportion of multiple antimicrobial-resistant isolates (96.4\%) in the dairy farms to antimicrobials that are commonly used in the veterinary and public health set up in this study further signifies the public health importance of Salmonella in addition to treatment failure. In this study, all the isolated Salmonella revealed resistance at least to one of the antibiotics tested. In general, awareness creation to the public about the public health importance of foodborne diseases and the consumption of unpasteurized milk and milk products is important. Gentamycin and Ciprofloxacin should still be used as a choice to treat Salmonellosis. Further, the molecular characterization of the isolates with emphasis on resistant strains is important to identify mechanisms of antibiotic resistance.

\section{References}

1. Megersa R, Mathewos M, Fesseha $H$ (2019) Isolation and Identification of Escherichia coli from Dairy Cow Raw Milk in Bishoftu Town, Central Ethiopia. Arch Vet Ani Sci 1

2. Jordan D (2007) Antimicrobial resistance in animals and impacts on food safety and public health. Microbiol Australia 28: 163-164.

3. Bedasa S, Shiferaw D, Abraha A, Moges T (2018) Occurrence and 
Citation: Fesseha H, Aliye S, Kifle T, Mathewos M. Isolation and Multiple Drug Resistance Patterns of Salmonella Isolates from Selected Dairy Farms in Hawassa Town, Ethiopia. J Veter Sci Med. 2020;8(1): 7.

antimicrobial susceptibility profile of Escherichia coli O157: $\mathrm{H} 7$ from food of animal origin in Bishoftu town, Central Ethiopia. Int $\mathrm{J}$ Food Contamination 5: 2

4. Ali AA, Irshad N, Razaz S, Manahil A (2010) Microbiological safety of raw milk in Khartoum state, Sudan: 1-Khartoum and Omdurman cities. Pakistan Journal of Nutrition 9: 426-429.

5. Control, C. f. D, and Prevention (2010) Surveillance for foodborne disease outbreaks---United States, 2007. MMWR. Morbidity and mortality weekly report 59: 973-979.

6. World Health Organization (2010) Global Foodborne Infections Network Laboratory Protocol. In "Isolation of Salmonella spp. From Food and Animal Faeces". WHO.

7. Wray C, Wray A (2000) "Salmonella in domestic animals," Cabi. 71.

8. Collazo CM, Galán JE (1997) The invasion-associated type-III protein secretion system in Salmonella-a review. Gene 192: 51-59.

9. Bäumler AJ, Tsolis RM, Ficht TA, Adams LG (1998) Evolution of Host Adaptation inSalmonella enterica. Infection and immunity 66: 4579-4587.

10. McCuddin Z, Carlson S, Sharma VK (2008) Experimental reproduction of bovine Salmonella encephalopathy using a norepinephrine-based stress model. Vet J 175: 82-88.

11. Uzzau S, Leori GS, Petruzzi V, Watson PR, Schianchi G, et al. (2001) Salmonella enterica serovar-host specificity does not correlate with the magnitude of intestinal invasion in sheep. Infection and immunity 69: 3092 3099.

12. Hoelzer K, Switt AIM, Wiedmann M (2011) Animal contact as a source of human non-typhoidal salmonellosis. Vet Res 42: 34.

13. Cummings KJ, Warnick LD, Elton M, Gröhn YT, McDonough PL, et al. (2010) The effect of clinical outbreaks of salmonellosis on the prevalence of fecal Salmonella shedding among dairy cattle in New York. Foodborne Pathogens and Disease 7: 815-823.

14. Perron GG, Quessy S, Bell G (2008) A reservoir of drug-resistant pathogenic bacteria in asymptomatic hosts. PLoS One 3: e3749.

15. USDA-APHIS (2011) Dairy 2007: Salmonella, Listeria, and Campylobacter on US dairy operations, 1996-2007.

16. World Health Organization (2003) Background document: the diagnosis, treatment and prevention of typhoid fever.

17. Beyene G, Asrat D, Mengistu Y, Aseffa A, Wain J (2008) Typhoid fever in Ethiopia. The Journal of Infection in Developing Countries 2: 448-453.

18. Addis Z, Kebede N, Sisay Z, Alemayehu H, Wubetie A, et al. (2011) Prevalence and antimicrobial resistance of Salmonella isolated from lactating cows and in contact humans in dairy farms of Addis Ababa: a cross sectional study. BMC Infectious Diseases 11: 222

19. Tajbakhsh F, Tajbakhsh E, Momeni M, Rahimi E, Sohrabi R (2012) Occurrence and antibiotic resistance of Salmonella spp Isolated from raw cow's milk from Shahahrekord, Iran. International Journal of Microbiological Research 3: 242-245.

20. Alexander KA, Warnick LD, Wiedmann M (2009) Antimicrobial resistan Salmonella in dairy cattle in the United States. Vet Res Communications 33: 191-209.

21. Zewdu E, Cornelius P (2009) Antimicrobial resistance pattern of Salmonella serotypes isolated from food items and personnel in Addis Ababa, Ethiopia. Tropical Animal Health And Production 41: 241-249.

22. Fluit AC (2005) Towards more virulent and antibiotic-resistant Salmonella? FEMS Immunology \& Medical Microbiol 43: 1-11

23. Beyene T, Tesega B (2014) Rational veterinary drug use: Its significance in public health. J Vet Med Animal Health 6: 302-308

24. Central Statistical Agency (2010) Central statistical agency agricultura sample survey In "Rep. Livestock Char,". Central Statistical Agency 236: 11 15.
25. Quinn PJ, Markey BK, Leonard FC, Hartigan P, Fanning S, et al. (2011) "Veterinary microbiology and microbial disease,". John Wiley \& Sons 928.

26. Clinical and Laboratory Standards Institute (2015) Performance Standards for Antimicrobial Susceptibility Testing; Twenty-fifth Informational Supplemen 35: 31-133. CLSI, 950 West Valley, RoadSuite 1500, Wayne, Pennsylvania, 19087-1898 USA.

27. Teklu A, Negussie $H$ (2011) Assessment of risk factors and prevalence of Salmonella in slaughtered small ruminants and environment in an export abattoir, Modjo, Ethiopia. Am Eurasian J Agric Environ Sci 10: 992-999.

28. Alemayehu D, Molla B, Muckle A (2003) Prevalence and antimicrobia resistance pattern of Salmonella isolates from apparently healthy slaughtered cattle in Ethiopia. Tropical animal health and production 35: 309-319

29. Nielsen LR (2003) Salmonella Dublin in dairy cattle: Use of diagnostic tests for investigation of risk factors and infection dynamics.

30. Tesfaw L, Taye B, Alemu S, Alemayehu H, Sisay Z, et al. (2013) Prevalence and antimicrobial resistance profile of Salmonella isolates from dairy products in Addis Ababa, Ethiopia. African J Microbiol Res 7: 5046-5050.

31. Abunna F, Ashenafi D, Beyene T, Ayana D, Mamo B, et al. (2017) Isolation identification and antimicrobial susceptibility profiles of Salmonella isolates from dairy farms in and around Modjo town, Ethiopia. Ethiopian Vet $\mathrm{J} 21$ : 92-108.

32. Assefa M, Teklu A, Negussie H (2011) The prevalence and public health importance of Salmonella from chicken table eggs, Ethiopia. AmericanEurasian. J Agric Environ Sci 11: 512-518

33. Tadesse T, Dabassa A (2012) Prevalence and antimicrobial resistance of Salmonella isolated from raw milk samples collected from Kersa district Jimma Zone, Southwest Ethiopia. J Med Sci 12: 224-228.

34. Davies R, Dalziel R, Gibbens J, Wilesmith J, Ryan J, et al. (2004) National survey for Salmonella in pigs, cattle and sheep at slaughter in Great Britain (1999-2000) J Appl Microbiol 96: 750-760.

35. Padungtod $P$, Kaneene JB (2006) Salmonella in food animals and humans in northern Thailand. I J Food Microbiol 108: 346-354.

36. Akoachere JFT, Tanih NF, Ndip LM, Ndip RN (2009) Phenotypic characterization of Salmonella typhimurium isolates from food-animals and abattoir drains in Buea, Cameroon. J Health Population Nutri 27: 612-618.

37. Blau D, McCluskey B, Ladely S, Dargatz D, Fedorka-Cray P, et al. (2005) Salmonella in dairy operations in the United States: prevalence and antimicrobial drug susceptibility. J Food Protection 68: 696-702.

38. Shilangale RP, Di Giannatale E, Chimwamurombe PM, Kaaya GP (2012) Prevalence and antimicrobial resistance pattern of Salmonella in animal feed produced in Namibia. Vet Ital 48: 125-132.

39. Mohamed O, Farid A, Abaza A, Faltas R (2011) Fecal shedding of nontyphoidal Salmonella species in dairy cattle and their attendants in Alexandria suburbs. J Am Sci 7: 623-631.

40. Callaway T, Keen J, Edrington T, Baumgard L, Spicer L, et al. (2005) Feca prevalence and diversity of Salmonella species in lactating dairy cattle in four states. J Dairy Sci 88: 3603-3608.

41. Bischoff K, Edrington T, Callaway T, Genovese K, Nisbet D (2004) Characterization of antimicrobial resistant Salmonella Kinshasa from dairy calves in Texas. Letters in applied Microbiol 38: 140-145.

42. Rodostits OM, Blood DC (1994) Veterinary Medicine: a text book of the disease of cattle, sheep, pigs, goats and horses. (8 edn). Boillière Tindall, London 1034 pp: 1763

43. Al Bahry S, El Shafie A, Al Busaidy S, Al Hinai J, Al Shidi I (2007) Antibioticresistant Salmonella spp. from human and non-human sources in Oman. East Mediterr Health J. 13: 49-55.

44. Khaitsa ML, Kegode RB, Doetkott DK (2007) Occurrence of antimicrobialresistant Salmonella species in raw and ready to eat turkey meat products from retail outlets in the midwestern United States. Foodborne Pathogens and Disease 4: 517-525. 
Citation: Fesseha H, Aliye S, Kifle T, Mathewos M. Isolation and Multiple Drug Resistance Patterns of Salmonella Isolates from Selected Dairy Farms in Hawassa Town, Ethiopia. J Veter Sci Med. 2020;8(1): 7.

ISSN: $2325-4645$

45. Rotimi VO, Jamal W, Pal T, Sonnevend A, Dimitrov TS, et al. (2008) Emergence of multidrug-resistant Salmonella spp. and isolates with reduced susceptibility to ciprofloxacin in Kuwait and the United Arab Emirates. Diagnostic Microbiol Infectious Disease 60: 71-77.

46. Stevens A, Kaboré Y, Perrier-Gros-Claude JD, Millemann Y, Brisabois A, et al. (2006) Prevalence and antibiotic-resistance of Salmonella isolated from beef sampled from the slaughterhouse and from retailers in Dakar (Senegal). Int J Food Microbiol 110: 178-186.

47. Mathew AG, Cissell R, Liamthong S (2007) Antibiotic resistance in bacteria associated with food animals: a United States perspective of livestock production. Foodborne Pathog Dis 4: 115-133.

48. McGeer AJ (1998) Agricultural antibiotics and resistance in human pathogens Villain or scapegoat? CMAJ 159: 1119-1120.

49. Fadlalla IM, Hamid ME, Rahim AGA, Ibrahim MT (2012) Antimicrobia susceptibility of Salmonella serotypes isolated from human and animals in Sudan. J Public Health Epidemiology 4: 19-23.

50. Dabassa A, Bacha K (2011) The Prevalence and Antibiogram of Salmonella and Shigella Isolated from Abattoir, Jimma Town, Southwestern Ethiopia. In "Conference of Jimma University" 3: 143-148. 